\title{
Determinants of Health Services Utilization among the Elderly in Calabar Municipality, Cross River State, Nigeria
}

\author{
Osuchukwu Nelson Chukwudi ${ }^{1}$, Inde Margaret Uyilewhoma ${ }^{2}$, Osuchukwu Easter Chukwudi, \\ Eko Jimmy Ebi ${ }^{1}$, O’Neill Mary Emmanuel ${ }^{4}$, Osonwa Okorie Kalu ${ }^{5}$, Ekpo Ekpo Iyamba ${ }^{2}$ \\ ${ }^{1}$ Department of Public Health, Faculty of Allied Medical Sciences, University of Calabar, Calabar, Nigeria \\ ${ }^{2}$ College of Health Technology, Calabar, Nigeria \\ ${ }^{3}$ Department of Nursing Sciences, Faculty of Allied Medical Sciences, University of Calabar, Calabar, Nigeria \\ ${ }^{4}$ Department of Environment Health, College of Health Technology, Calabar, Nigeria \\ ${ }^{5}$ Department of Sociology, Faculty of Social Sciences, University of Calabar, Calabar, Nigeria
}

\section{Email address:}

nelsonosuchukwu@yahoo.com (N. C. Osuchukwu), Indemargaret@gmail.com (M. U. Inde), nelsonosuchukwu@yahoo.com (E.C. Osuchukwu),jimmyeko25@gmail.com (J. E. Eko), mary_egbun@yahoo.com (M. E. O’Neill), emekusi@yahoo.com(O.K. Osonwa),iyamba94@gmail.com (E. I. Ekpo)

\section{To cite this article:}

Osuchukwu Nelson Chukwudi, Inde Margaret Uyilewhoma, Osuchukwu Easter Chukwudi, Eko Jimmy Ebi, O’Neill Mary Emmanuel, Osonwa Okorie Kalu, Ekpo Ekpo Iyamba. Determinants of Health Services Utilization among the Elderly in Calabar Municipality, Cross River State, Nigeria. European Journal of Preventive Medicine. Vol. 3, No. 5, 2015, pp. 129-136. doi: 10.11648/j.ejpm.20150305.11

\begin{abstract}
Background: Geriatric healthcare is increasingly becoming a component of the healthcare delivery system as the reality of healthcare for the elderly varies dramatically from one society to another. Objective: The general objective of this study was to identify the determinants of healthcare services utilization among the elderly in Calabar Municipality, Cross River State, Nigeria. Methods: A semi-structured questionnaire was used to generate data from 200 respondents using multi-stage sampling technique. Data generated were analyzed using statistical package for social sciences (SPSS version 20.0) and results were presented in tables and charts. Chi-square was used to test for association between variables at 5\% level of significance. Results: The result of this study showed that most respondents were aged 65-69years 74(37.0\%) followed by those aged 70-74years 56(28.0\%) and 75-79years 42(21.0\%). More females $110(55 \%)$ than males $90(45 \%)$ participated in the study. More than half of the respondents 34(67\%) reported to have visited the hospital in the last 12 months mainly for general body checkup 51(25.5\%) and treatment 31(15.5\%). Barriers to utilization of healthcare services identified in this study include; long waiting time $10(22.2 \%)$, drug prescribed not available $10(22.2 \%)$ and health workers not friendly 10(22.2\%). Factors associated with health services utilisation among the elderly were gender, residential status, educational status, occupational status and income level $(\mathrm{P}<0.05)$. Conclusion: Proffering solutions to barriers to health services utilization highlighted in this study would promote optimal use of health services thereby improving the quality of life of the aged population.
\end{abstract}

Keywords: Elderly, Health Services, Determinants, Calabar Municipality

\section{Introduction}

Globally, it has been observed that individuals who are 65 years and above approximately accounts for about $2 \%$ of the total world population. The proportion of the aged population would substantially increase from less than 90 million in 2005 to almost 400 million in 2050 [1]. In most developing countries, recent studies have shown that a gradual increase in average life expectancy and a higher proportion of the aged population is significantly influenced by demographic changes. This increase consequently creates a growing pressure on the public health care delivery system.

Provision of health care services for older people is different across countries, continents and cultural societies. In developed regions of the world, health care is often provided by well-equipped public health facilities and nursing homes designated for the elderly individuals. In 
United States, older adults have a higher frequency of primary care visit, $50 \%$ hospital consultation, $80 \%$ home care services and occupy $90 \%$ of all nursing home beds [2]. Paradoxically, in developing regions, the picture is rather different as the contemporary health care facilities might not be the first point of contact for an elderly person.

In most Sub-saharan African countries, availability and utilization of health care services among the elderly is poorly reported. For instance, a study carried out in Democratic Republic of Congo revealed that more than half of the elderly people $(55.6 \%)$ consulted private facilities and traditional spiritual healers once they were ill. The public health facility was used by only $3.3 \%$ elderly persons (3). A Ghanaian, reported that in the last three years, about one-third of the elderly (31.5\%) utilize health care [4].

In Nigeria, geriatrics care has not yet received its desire attention. Most elderly persons utilize the conventional health care facilities whenever they fall ill while others subscribe to self medication with orthodox medicine and traditional herbs. In Calabar Municipality, there are no known available social support services, elderly homes and designated health facilities where health care for the elderly population is priortised. In some situations, most elderly persons tend to depend on their families, relatives and friends for utmost care. This accounts for why they are care-dependent. However, studies have shown that utilization of health care services among the elderly is suboptimal. A study carried out in Delta State in Nigeria reported that about $40.56 \%$ of the elderly patronized chemists and pharmacist's shop, $19.44 \%$ patronized traditional healers/herbalists, $16.67 \%$ and $15.55 \%$ of the respondents got their medical needs from medical hawkers and self medication and only $17.18 \%$ sought treatment from regular hospitals and clinics (5). In another household survey in Kwara State, Nigeria, most elderly persons (44. $6 \%$ ) reported that family care/family consultation was the first choice of treatment for the most frequently reported illnesses irrespective of age group and sex (6).

A conglomerate of research has shown that certain factors are responsible for the gross under-utilization of health services by the elderly. Barriers to utilization of health services could occur at the patient's level, health care provider's level and the organizational level [7]. It has been observed that distance, waiting time and attitude of health workers hinders adequate access and use of health services especially among older adults [8]. A qualitative follow-up study in Hong Kong reported that barriers to access and utilization of health services include; lack of knowledge about aged care services, poor transport system, long waiting time, lack of services during non- offices hours, lack of accommodation for people with disability or dementia and a complication of procedure (9). A population-based study carried out in South Africa revealed that, factors influencing utilization of eye care services include level of income, knowledge of available services and the need for regular eye tests (10). A household survey carried out in Nigeria revealed that a number of factors such as poverty $(50.3 \%)$ followed by nature of illness $(25.2 \%)$, quality of service provided $(10.8 \%)$, attitude of health caregivers $(3.6 \%)$, waiting time $(3 \%)$, availability of service $(2.8 \%)$, distance $(2.3 \%)$ and level of education $(2 \%)$ influence healthcare seeking behaviour among the elderly (6). [11] also reported in their study that high cost of drugs $(72.0 \%)$, non availability of essential drugs (54.8\%), time spent waiting for treatment $(67.2 \%)$, inadequate referral services $(81.7 \%)$, and satisfaction with services $(60.6 \%)$ were identified as factors affecting the utilization of health services. A study in Edo State, Nigeria reported that waiting time $(70.5 \%)$, insufficient number of doctors $(66 \%)$, high cost of health services (53\%) were factors that could prevent the elderly from subsequent utilization of health services (12). Aging process and problems related to the elderly should be better understood so that effective elderly health prevention can be planned and implemented [13]. Thus, in order to meet the health needs of the poor and disadvantaged elderly it is crucial that their view on barriers to health services utilization and satisfaction with the quality of care is given utmost priority.

\section{Objective of the Study}

The objective of this study was to identify the determinants of health services utilization among the elderly in Calabar municipality, Cross River State, Nigeria.

\section{Methodology}

\subsection{Study Setting}

The study area is Calabar Municipality. It is situated in the Southern Senatorial District of Cross River State, Nigeria. Calabar Municipality is made up of an estimated population of 176,218 (14). Calabar Municipal council has 10 political wards with a land mass of 141.33 square kilometer. The Area is bounded by Calabar River to the west, Akpabuyo Local Government Area to the east, Odukpani Local Government Area to the north and Atlantic Ocean to the south. It is a cosmopolitan city which embraces all ethnic groups in Nigeria. The two dominant ethnic groups are the Efiks and Quas which share common culture and religion. English and Efik are the languages widely spoken. The municipal is predominantly a Christian city with few Muslims and traditional religious groups and mainly occupied by civil servants, businessmen and traders. It also has industries and establishments such as airport, export processing zone, Naval and Army base, Tinapa, NNPC depot, cement factory etc. The municipal has three levels of health care namely; primary, secondary, tertiary level as well as private health care. Calabar is famous for its rich cultural heritage, warm hospitality and peace-loving disposition.

\subsection{Study Design}

A cross-sectional descriptive study design was employed 
to identify the determinants of health services utilization among the elderly in Calabar Municipality, Cross River State, Nigeria.

\subsection{Study Population}

The study population comprised all elderly persons that are 65 to 90years in Calabar Municipality, Cross River State, Nigeria. Elderly persons with hearing defect and the dumb were excluded from participating in the study.

\subsection{Sample Size Determination}

Sample size for this study was determined using Fishers' formula, (15) which is given as

$$
\mathrm{n}=\frac{\mathrm{Z}^{2} \mathrm{Pq}}{\mathrm{d}^{2}}
$$

Where $\mathrm{n}=$ Sample size

$Z=1.96$ (i.e. $95 \%$ confidence interval)

$\mathrm{d}=0.06$ (acceptable margin of error)

$\mathrm{P}=17.78 \%=0.18$ (Proportion of elderly persons utilizing health care services) (Okumagba, 2011)

$\mathrm{q}=1-\mathrm{P}=0.82$ (Proportion of elderly persons not utilizing health care services)

$$
\text { Therefore, } \mathrm{n}=\frac{(1.96)^{2} \times 0.18 \times 0.82}{(0.06)^{2}}=158
$$

The sample size for this survey was 158. However, to make room for non-response and attrition bias, the desired sample size was increased by $20 \%$ giving a sample size of 200 that was used for the study.

\subsection{Sampling Procedure}

Multi-stage random sampling technique was employed in the selection of wards, streets, household and respondents and the procedure is described as follows:

Stage 1: Random sampling was employed to select 5 wards using the lottery method. Numbers were assigned to each ward, folded, put in a basket and shaken vigorously. Someone (research assistant) was asked to pick a piece of the folded paper after which it was shaken until all that were considered for the study were picked.

Stage 2: In each selected ward, simple random sampling technique was employed to select 4 streets from each ward using the lottery method. Numbers were assigned to each street, folded and put in a basket. It was shaken vigorously and picked by a research assistant which gave a total of 20 streets.

Stage 3: In each selected street, systematic sampling technique was employed to select households with an elderly person that are 65 to 90years excluding elderly with hearing/dumb defect. This procedure continued until 10 households were duly selected from 20 streets (i.e. 10 households x 20 streets $=200$ elderly persons).

Stage 4: Selection of respondents: In each household, simple random sampling method was employed to select respondents using lottery methods.

\subsection{Instrument for Data Collection}

A semi-structured questionnaire was designed to generate quantitative data from the respondents. The questionnaires were administered to respondents that gave their consent to participate in the study. It comprised two sections and 15 items. Sections A comprised socio-demographic characteristics while Section B comprised utilization of health care services by the elderly respectively. The questionnaire was pre-tested among 20 (i.e. 5\% of sample size) elderly people residing in Calabar South Local Government Area. The essence of pre-testing the questionnaire is to ascertain its reliability and validity. Pretesting helped to determine the relevance of questions and variables under measurement, remove ambiguity where it exists, improve on sequencing of questions and estimate maximum time for completion of questionnaires.

\subsection{Method of Data Analysis}

Data entry and analysis were done using the Statistical Package for Social Sciences Software (SPSS 20.0 version, 2012) and Microsoft excel 2007. Results were expressed as percentages and presented in tables and charts. Chi-square was used to test for association between variables at 5\% level of significance.

\subsection{Ethical Consideration}

A letter of introduction was collected from the department of public health, University of Calabar, Calabar. This letter was used as an entry point to the study area. Verbal informed consent was duly sought and obtained from the respondents that took part in the study. The objectives, significant and benefits of the study were explained to the respondents and participation in this study was strictly voluntary. The research participants were assured of confidentiality of information volunteered by them.

\section{Results}

\subsection{Socio-demographic Characteristics of the Respondents}

Two-hundred copies of the questionnaire were administered to the respondents and the response rate was $100 \%$. The demographic distributions of the respondents were as follows: most respondents were aged 65-69 years $74(37.0 \%)$ while others were aged $70-74$ years $56(28.0 \%)$ and $75-79$ years $42(21.0 \%)$. There were $110(55.0 \%)$ females while $90(45.0 \%)$ were males. Respondents staying with their family members were $92(46.0 \%)$ while $60(30.0 \%)$ reported staying with their spouse and 48(24.0\%) said they stay alone. Religion affiliation revealed that Christians were 174(87.0\%), Muslims 10(5.0\%) and traditionalists 16(8.0\%). Most respondents were married 104(52.0\%), 54(27.0\%) widow/widower while $26(13 \%)$ single. Those who had tertiary education were $96(48.0 \%)$, secondary $42(21.0 \%)$, primary $24(12.0 \%)$ while $38(19.0 \%)$ had no formal education (Table 1). 
Table 1. Distribution of respondents by age, sex, residential status, religion, marital status and educational status $(n=200)$.

\begin{tabular}{lll}
\hline Variables & Number of respondents & Percentage (\%) \\
\hline Age in years & & \\
$65-69$ & 74 & 37.0 \\
$70-74$ & 56 & 28.0 \\
$75-79$ & 42 & 21.0 \\
$80-84$ & 16 & 8.0 \\
85 and above & 12 & 6.0 \\
Total & 200 & 100 \\
Sex & & \\
Male & 90 & 45.0 \\
Female & 110 & 55.0 \\
Total & 200 & 100 \\
Residential status & & \\
Living alone & 48 & 24.0 \\
Living with family & 92 & 46.0 \\
members & 60 & 30.0 \\
Living with spouse & 200 & 100 \\
Total & & \\
Religion & 174 & 87.0 \\
Christianity & 10 & 5.0 \\
Muslims & 16 & 8.0 \\
Traditional religion & 200 & 100 \\
Total & & \\
Marital status & 26 & 13.0 \\
Single & 104 & 52.0 \\
Married & 8 & 4.0 \\
Divorced & 8 & 4.0 \\
Separated & 54 & 27.0 \\
Widow/widower & 200 & 100 \\
Total & & \\
Educational status & 38 & 19.0 \\
No formal education & 24 & 12.0 \\
Primary education & 42 & 21.0 \\
Secondary education & 96 & 48.0 \\
Tertiary education & 200 & 100 \\
Total & & \\
\hline & & \\
\hline
\end{tabular}

\subsection{Distribution of Respondents According to Their Occupational Status and Income Level}

Most of the respondents $135(67.5 \%)$ had not worked in the last 12 months. The remaining 65(32.5\%) respondents were government employees 19(9.5\%), selfemployed/business/farming $10(5.0 \%)$ and private employment $8(4.0 \%)$. About $28(14.0 \%)$ said they were pensioners. Income mostly earned range between N11,000$\mathrm{N} 40,000 \quad 21(10.5 \%), \quad \mathrm{N} 40,000-\mathrm{N} 50,000 \quad 18(9.0 \%)$ and N50,000 and above 11(5.5\%) (Table 2).

Table 2. Distribution of respondents according to their occupational status and level of income $(n=200)$.

\begin{tabular}{lll}
\hline Variables & $\begin{array}{l}\text { Number of } \\
\text { respondents }\end{array}$ & $\begin{array}{l}\text { Percentage } \\
\text { (\%) }\end{array}$ \\
\hline Occupational status & & \\
Worked within the last 12 months & 65 & 32.5 \\
Not worked in the last 12 months & 135 & 67.5 \\
Total & 200 & 100 \\
Type of occupation & & \\
Pensioner & 28 & 14.0 \\
Self-employed/ business/ farming & 10 & 5.0 \\
Government employment & 19 & 9.5 \\
Private employment & 8 & 4.0 \\
\hline
\end{tabular}

\begin{tabular}{lll}
\hline Variables & $\begin{array}{l}\text { Number of } \\
\text { respondents }\end{array}$ & $\begin{array}{l}\text { Percentage } \\
(\%)\end{array}$ \\
\hline No response & 135 & 67.5 \\
Total & 200 & 100 \\
Income level & & \\
Less than N5,000 & 5 & 2.5 \\
N6,000-N10,000 & 10 & 5.0 \\
N11,000-40,000 & 21 & 10.5 \\
N41,000-N50,000 & 18 & 9.0 \\
N50,000 and above & 11 & 5.5 \\
No response & 135 & 67.5 \\
Total & 200 & 100 \\
\hline
\end{tabular}

\subsection{Utilization of Health Care Services among Respondents}

Most respondents $82(41.0 \%)$ only visit the hospital/health center just once in a year. Others reported that they visit the hospital/health center at least twice $54(27.0 \%)$, thrice $34(17.0 \%)$ or four times $30(15.0 \%)$ in a year. In the last 12 months, about $134(67.0 \%)$ reported to have visited the hospital/health center whereas 66(33.0\%) never visited any health facility in a space of one year. Female elderly (67.2\%) were higher users of health care services than their male counterparts $(32.8 \%)$ (Figure 1). Reasons that necessitated hospital visits irrespective of the frequency include; general body checkup 50(25\%), treatment 31(15.5\%), ill-health 21(10.5\%), counseling 17(8.5\%) and appointment with doctor $15(7.5 \%)$. Among the $134(67.0 \%)$ who had visited to hospital in the last 12 months, $89(44.5 \%)$ respondents said they were well attended to and would like to repeat the visit to the hospital/health center, whereas $45(22.5 \%)$ completely stated otherwise (Table 3).

Table 3. Utilization of healthcare services among respondents $(n=200)$.

\begin{tabular}{lll}
\hline Variables & Number of respondents & Percentage (\%) \\
\hline \multicolumn{2}{l}{ Frequency of hospital visit } & \\
Once a year & 82 & 41.0 \\
Twice a year & 54 & 27.0 \\
Thrice a year & 34 & 17.0 \\
Four times and above & 30 & 15.0 \\
Total & 200 & 100 \\
Hospital /health center visit in the last 12 months & \\
Yes & 134 & 67.0 \\
No & 66 & 33.0 \\
Total & 200 & 100 \\
Reasons for hospital & & \\
visit & & \\
General body checkup & 50 & 25.0 \\
Ill-health & 21 & 10.5 \\
Counseling & 17 & 8.5 \\
Appointment with & 15 & 7.5 \\
doctor & 31 & 15.5 \\
Treatment & 66 & 33.0 \\
No response & 200 & 100 \\
Total & 89 & 44.5 \\
Would like to repeat visit to the Hospital/health center & \\
Yes & 45 & 22.5 \\
No & 66 & 33.0 \\
No response & 200 & 100 \\
Total & & \\
\hline
\end{tabular}




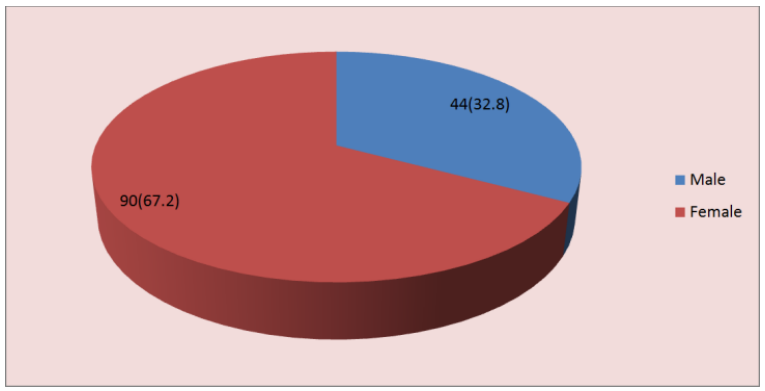

Fig. 1. Proportion of respondents utilizing health services according to gender.

\subsection{Respondents' Reasons for Regular Hospital Visits}

Reasons that would warrant regular hospital visits according to the respondents include; effectiveness of treatment $25(12.5 \%)$, availability of essential drugs $18(9.0 \%)$, effectiveness of medical equipments $14(7.0 \%)$, easy access to doctor $12(6.0 \%)$, health workers friendly $8(4.0 \%)$ and proximity to health center $6(3.0 \%)$ (Figure 2$)$.

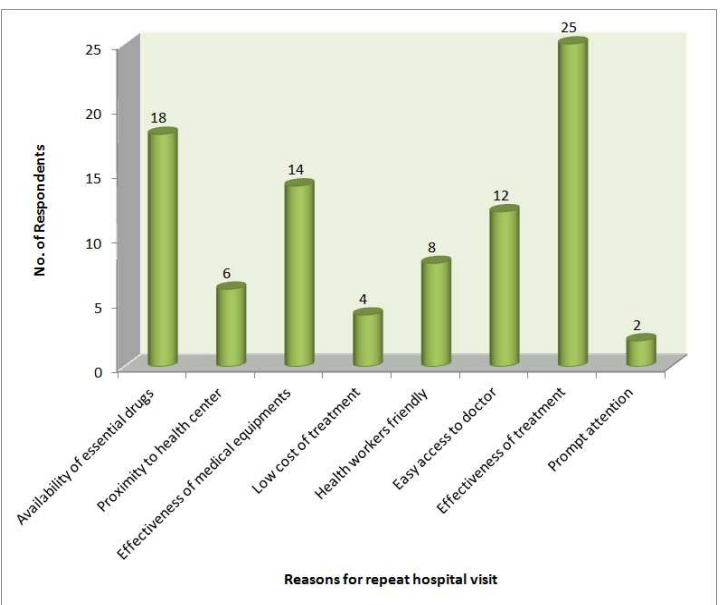

Fig. 2. Respondents' reasons that would encourage regular hospital/health center visit.

Table 4. The relationship between utilization of health services and socio-demographic characteristics of the elderly using Chi-square.

\begin{tabular}{|c|c|c|c|c|c|c|c|}
\hline \multirow{2}{*}{$\begin{array}{l}\text { Socio-demographic } \\
\text { characteristics }\end{array}$} & \multicolumn{3}{|c|}{ Utilization of health services in the last 12 months } & \multirow[t]{2}{*}{ df } & \multirow[t]{2}{*}{$\mathrm{X}^{2}$ Critical } & \multirow[t]{2}{*}{$\mathbf{X}_{0.05}^{2}$} & \multirow[t]{2}{*}{ P-value } \\
\hline & Used health services & Not used health services & Total & & & & \\
\hline Age in years & & & & 4 & 7.09 & 9.49 & $>0.05$ \\
\hline $65-69$ & 47 & 27 & 74 & & & & \\
\hline $70-74$ & 41 & 15 & 56 & & & & \\
\hline $75-79$ & 32 & 10 & 42 & & & & \\
\hline $80-84$ & 8 & 8 & 16 & & & & \\
\hline 85 and above & 6 & 6 & 12 & & & & \\
\hline Male & 44 & 46 & 90 & & & & \\
\hline Female & 90 & 20 & 110 & & & & \\
\hline Residential status & & & & 2 & 7.005 & 5.99 & $<0.05$ \\
\hline Living alone & 17 & 31 & 48 & & & & \\
\hline Living with family members & 78 & 14 & 92 & & & & \\
\hline Living with spouse & 39 & 21 & 60 & & & & \\
\hline Religion & & & & 2 & 5.344 & 5.99 & $>0.05$ \\
\hline Traditional religion & 3 & 13 & 16 & & & & \\
\hline Marital status & & & & 4 & 8.333 & 9.49 & $>0.05$ \\
\hline
\end{tabular}

\subsection{Barriers to Utilization of Health Care Services among Respondents}

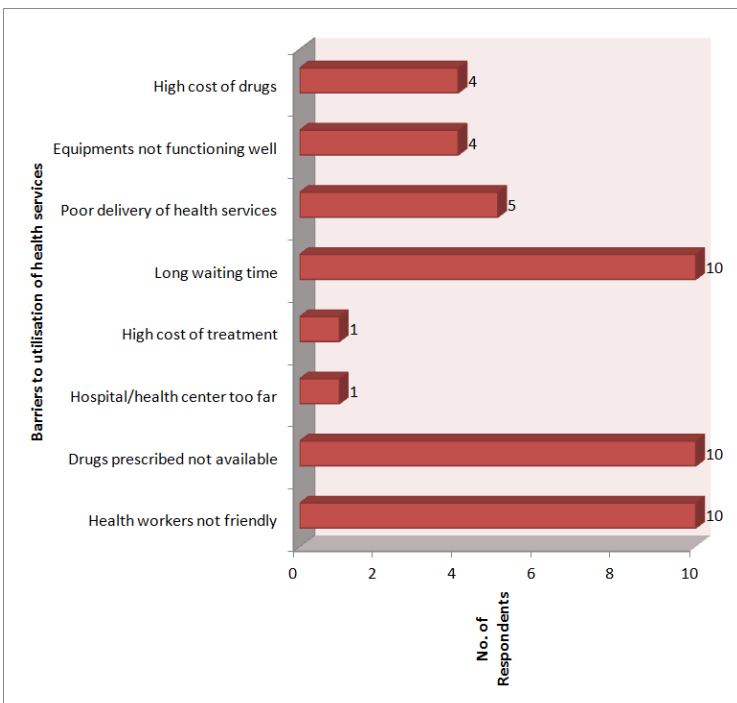

Fig. 3. Barriers to utilization of health care services among respondents .

Barriers to utilization of health services identified by the respondents include; long waiting time 10(22.2\%), drug prescribed not available $10(22.2 \%)$, health workers not friendly $10(22.2 \%)$, poor delivery of health services $5(11.1 \%)$, equipment not functioning well $4(8.9 \%)$ and high cost of drugs $4(8.9 \%)$ (Figure 3). Factors associated with health services utilisation among the elderly were gender, residential status, educational status, occupational status and income level $(\mathrm{P}<0.05)$ (Table 4). 


\begin{tabular}{|c|c|c|c|c|c|c|c|}
\hline \multirow{2}{*}{$\begin{array}{l}\text { Socio-demographic } \\
\text { characteristics }\end{array}$} & \multicolumn{3}{|c|}{ Utilization of health services in the last 12 months } & \multirow[t]{2}{*}{ df } & \multirow[t]{2}{*}{$\mathrm{X}^{2}$ Critical } & \multirow[t]{2}{*}{$\mathbf{X}_{0.05}^{2}$} & \multirow[t]{2}{*}{ P-value } \\
\hline & Used health services & Not used health services & Total & & & & \\
\hline Single & 17 & 9 & 26 & & & & \\
\hline Married & 77 & 27 & 104 & & & & \\
\hline Divorced & 5 & 3 & 8 & & & & \\
\hline Separated & 6 & 2 & 8 & & & & \\
\hline Widow/widower & 29 & 25 & 54 & & & & \\
\hline Educational status & & & & 3 & 12.04 & 7.81 & $<0.05$ \\
\hline No formal education & 12 & 26 & 38 & & & & \\
\hline Primary education & 10 & 14 & 24 & & & & \\
\hline Secondary education & 31 & 11 & 42 & & & & \\
\hline Tertiary education & 81 & 15 & 96 & & & & \\
\hline Occupational status & & & & 1 & 6.0354 & 3.84 & $<0.05$ \\
\hline Worked within the last 12 months & 62 & 3 & 65 & & & & \\
\hline Not worked in the last 12 months & 72 & 63 & 135 & & & & \\
\hline Income level & & & & 2 & 11.3042 & 5.99 & $<0.05$ \\
\hline High & 9 & 0 & 9 & & & & \\
\hline Medium & 49 & 1 & 50 & & & & \\
\hline Low & 4 & 2 & 6 & & & & \\
\hline
\end{tabular}

\section{Discussion}

Majority of the respondents (41.0\%) reported to have visited the hospital/health center just once a year, whereas others reported that they visit the hospital at least twice (27\%), thrice (17.0\%) and four times and above (15\%) in a years. The frequency of hospital visit largely depends on the frequency of occurrences of health problem or illness, severity of the illness and adherence to treatment regimen. Since most elderly persons are care-dependent, the availability of supportive care from family members, friends or family physicians also influences their frequency of hospital visit. In the last 12 months, more than half of the respondents $(67.0 \%)$ reported to have visited the health facility while $33 \%$ said they had not visited any health facility in the last 12 months. From this report, it is obvious that most elderly people suffer recurrent health problems that have necessitated more hospital visit. Adherence to treatment regimen may also contribute to increase utilization of health facilities. It can also be hypothesized that, in most urban setting, most elderly person have absolute confidence in the quality and efficacy of health care services rendered by both government-owned and private facilities than other health care outlets. This also may have significant influence increase hospital visit. This result disagrees with a household survey carried out in Illorin, Nigeria where $68.8 \%$ of the respondents never visited any health facilities and only $31.2 \%$ visited the health facility at least once a year (6). Reasons for hospital visits were majorly for general body checkup (25.5\%), treatment $(15.5 \%)$ and ill-health (10.5\%). Counseling (9.5\%) and appointment with doctor $(8.5 \%)$ were the least reasons for hospital visit as reported by the respondents. This report is comparable to that of (6) where most elderly persons $(89.4 \%)$ visited the hospital mainly for treatment. Aside general body diagnosis which is highly recommended by health care providers before administering treatment, adherence to treatment regimens has largely accounted for most hospital visits. This is so because, absolute recovery from ill-health is highly dependent on the adherence rate to treatment prescribed.

Out of $67 \%$ who reported to have visited the health facility in the last 12 months, about $44.5 \%$ said they were satisfied with services received and would repeat visit to the health facility when the need arises whereas $22.5 \%$ stated otherwise. The level of satisfaction with health care received is dependent on the type of services sought for, availability of services, effectiveness of medical equipments and competence of health care providers to managed complex health needs of the elderly. Factors that would influence regular hospital visits among respondents who were satisfied with their last visit include; effectiveness of treatment (28.1\%), availability of essential drugs (20.2\%), effectiveness of medical equipments $(15.7 \%)$ and easy access to doctor $(13.5 \%)$. These indicators are pivotal to effective delivery of quality health care services to the aged population. Improving services delivery in these aspects of health care is highly recommended to enhance utilization of health services among the elderly.

This study adopted [7] system of categorizing barriers to health service utilization at the patient's level, health care provider's level and organization level. In the study, barriers to health care utilization identified by respondents at the patient's level include; distance to health facility, high cost of treatment, high cost of drugs. This was largely reported by those who were unemployed and those who earned less income. This report corroborates with that of (8) where distance to health facility was most identified as a major factor responsible for under-utilization of health services. A study in Hong Kong also confirmed that poor transport system contributed to sub-optimal use of health care services (9). While (12) identified high cost of health services, (11) identified high cost of drugs as factors affecting health seeking behaviour. Since most elderly persons are caredependent, adequate provision of ambulatory services, subsidizing the cost of drugs and cost of treatment would eventually facilitate optimal use of health care services among the aged population.

At the health care provider's level, barriers identified by 
respondents include; unfriendly attitude towards patients and poor delivery of health services. This finding is similarly reported in other studies where attitude of health workers was recognized as a major factor affecting the use of health care services $(6,8)$. A Ugandian study revealed that patients underutilized health services at public facilities because health workers tend to minimize their attention towards poor women who were unable to afford soap, clothes and simple gloves (8). This usually results in self-medication mostly with traditional herbs which are easily accessible. Notably, absence of health workers-patient relationship has also resulted in poor delivery of health services. Training health workers on geriatrics care is pivotal to improved delivery of quality health care to the elderly. Special support care should also be given to those elderly persons suffering from any form of disability.

At the organizational level, barriers clearly identified include; long waiting time, non-availability of drug prescribed and dysfunction of diagnostic equipment. This result is comparable with that of (8) who identified long waiting time as a barrier to optimal use of health services. (11) also identified long waiting time and non-availability of essential drugs as factors affecting utilization of health services. Long waiting time has long been an issue in most contemporary health institutions. The growing influx of patients into government-owned facilities where treatment is reportedly affordability out-weighs the number of health workers attending to these patients. Shortage and poor distribution of health workers have contributed substantially to long waiting time in most health care institutions. Continual training, recruitment and appropriate distribution of health workers would significantly minimize patient waiting time in health care facilities. The government should also ensure regular provision of essential drugs and diagnostic medical equipment in all health care institutions.

Factors associated with health services utilisation among the elderly were gender, residential status, educational status, occupational status and income level $(\mathrm{P}<0.05)$. It was observed that females were higher users of health services than males. Elderly people who were living with family members and their spouses were more likely to use health services than those who were staying alone. Higher income earners, higher educational status and employment status were significantly associated with regular use of health services.

\section{Conclusion}

Geriatric health care is increasingly becoming a core component of the health care delivery system. In most third world countries, effective delivery of geriatric care is still sub-optimal due to poor health policies, lack of facilities and poor welfare scheme for the elderly. Although, utilization of health care services among the elderly in this study was substantially high, other elderly persons (especially elderly males) who rarely visit the health facility when they fall sick need to be reached. Proffering solutions to barriers to health services utilization highlighted in this study would promote optimal use of health services, reduce morbidity and mortality rate from infectious and non-infectious disease thereby increase life expectancy and quality of life of the aged populace.

\section{Recommendations}

Based on the findings from this study, the following recommendations are made;

1. Health care providers should be trained on geriatric care as this would enhance optimal delivery of quality health services, improve health care seeking behaviour among the elderly and offer referrals services where necessary through provision of vital hospital equipments.

2. Management of health care institutions should ensure that trained health workers are appropriately distributed to the different health care facilities to ensure equal service delivery.

3. Health care for the elderly should be incorporated as one of the core in annual health planning, policy formulation and intervention programmes as well as incorporating geriatric care into the National Health Insurance Scheme (NHIS) programme so that the aged population will benefit from free treatment, free drugs and subsidized specialist care.

\section{References}

[1] United Nations. World Aging population. 2007; Available at www.un.org/esa/ population/publications/ WPA2007/ESEnglish.pdf

[2] Mezey M. Fulmer T. Quality care for the frail elderly. Nursing Outlook, 1998; 46(6):291-292.

[3] Lutala M. P., Kwalya T. M., Kasagila E. K., Watongoka L. H., Mupenda B. W. Health care seeking and financial behaviours of the elderly during wartime in Goma, Democratic Republic of Congo. Afr J Prm Health Care Fam Med; 2010; 2(1):108114

[4] Exavery A., Klipstein-Grobusch K., Debpuur C. Self-rated health and health care utilization among rural elderly Ghanaians in Kassena-Nankana district. 2011 Available at uaps2011.princeton.edu/papers/1103321-30.

[5] Okumagba P. O. Choice of health care services utilization by the elderly in Delta State in Nigeria. J Sociology Soc. Anth; 2011; 2(2):131-138.

[6] Abdulraheem I. S. Health Needs Assessment and Determinants of Health-Seeking Behaviour among Elderly Nigerians: A House-Hold Survey. Annals of African Medicine; 2007; 6:58-63.

[7] Scheppersa, E., Dongenb, E., Dekkerc, J.,Geertzend J., Dekkere J. Potential barriers to the use of health services among ethnic minorities: a review. Oxford Journals Medicine $\&$ Health Family Practice 2005; 23(3): 325-348

[8] Soai M. Distance, time and health workers' attitude: How they determine people's view towards the health care system. Med Care Analysis; 2012; 1(2): 12-15 
[9] Chou K. L., Chi I., Chong A. M. L. The utilization of aged care services by the frail elderly and their family caregivers. Hong kong Med J. 2006; 12(2):7-9

[10] Ntsoane M. D., Oduntan O. A., Mpolokeng B. L. Utilization of public eye care services by the rural community residents in the Capricorn district, Limpopo Province, South Africa. Afr $J$ Prm Health Care Fam Med.;2012; 4(1):7-12

[11] Obiechina G. O., Ekenedo G. O. Factors affecting utilization of University health services in a tertiary institution in SouthWest Nigeria. Niger J Clin Pract; 2013; 16:454-7

[12] Agbogidi J., Azodo C. Experiences Of The Elderly Utilizing Healthcare Services In Edo State. The Internet Journal of
Geriatrics and Gerontology. 2009; 5(2): 23-77.

[13] Moe S., K. Tha, Naing D.K.S. and. Htike, M.M.T. Health seeking behavior of elderly in Myanmar, International Journal of Collaborative Research on Internal Medicine and Public Health, 2012; 4(8): 1538-1544

[14] National population commission, Projected population of Calabr South Local Government Area of Cross River State, Nigeria. 2006; Retrieved on January 14, 2012 from http//www.citypopulation.de

[15] Fisher, R. A. "On the interpretation of $\chi^{2}$ from contingency tables, and the calculation of P". Journal of the Royal Statistical Society 1945; 85(1): 87-94. 